during late Ordovician plate movements.

$\mathrm{He}$ also discussed the functional aspects of respiration in cystids to critically low oxygen levels in shallow tropical seas. This linked the palaeogeographic approach to the climatic one which was discussed by $\mathrm{N}$. Spjeldnaes (University of Aarhus, Denmark). The now well known glacial deposits of the Moroccan AntiAtlas were beautifully illustrated by $\mathbf{J}$. Destombes (Service géologique, Rabat) and other speakers referred to climatic cycles in the Ordovician which influenced the occurrence of various groups of fossils. Changes in faunas could be caused as much by climatic changes as by migration between continental plate margins and the disentangling of plate movements through the whole length of the Ordovician needs much further work.

None of the formal papers included any discussion of the boundaries of the Ordovician, most speakers making it clear whether they regarded the Tremadocian as Cambrian (as in English usage) or Ordovician. But the large gathering of experts from so many countries, including the Soviet Union, provided the opportunity for meetings of the Commission on Stratigraphy of the International Union of Geological Sciences. Several recently formed subcommissions and working groups of the commission will have a great deal to do with correlation of strata between countries and continents. Differences of interpretation were much in evidence during the closing general discussion in Birmingham, particularly between those based on groups of fossils traditionally used, such as brachiopods and trilobites, and those which have come into prominence in the last few years, such as conodonts. Some of the ideas were certainly provocative and augur well for the future liveliness of the subject. As an eminent worker on Palaeozoic gastropods put it to close the meeting - a snail never gets anywhere unless he sticks his neck out.

\section{Plant conifers and lose water}

from Peter D. Moore

A KNOWLEDGE of the rate of water loss from a forest is essential both for forest water budget calculations and in the management of water catchments. Many comparative studies have been undertaken to provide such information, on forest stands and on other vegetation types. Differences in water loss from various types of vegetation are explicable in terms of transpiration rates, in the effect of vegetation upon evaporation direct from the soil by

\title{
Expanding wings in moths
}

\section{from our Insect Physiology Correspondent}

EVERY lepidopterist knows that emerging butterflies and moths go through a characteristic sequence of wing-folding movements, with wing expansion and general hardening of the cuticle, before settling down into their normal resting posture; and that the force for wing expansion is the hydrostatic pressure of the blood generated by strong contraction of the abdomen. Truman and Endo (J. exp. Biol., 61, 47 ; 1974) have now elucidated the complex of physiological factors engaged in this familiar phenomenon.

It was shown by Fraenkel many years ago that if the newly moulted blowfly is obliged to continue burrowing through the soil, it remains soft with the wings and body unexpanded for many hours. Only when it makes its escape is the cuticle expanded, hardened and darkened. It was generally assumed that this hardening process must be controlled by a hormone, but that was demonstrated by Cottrell only in quite recent years and confirmed by Fraenkel and Hsiao, who named the hormone in question 'bursicon'. It is liberated from the brain and other ganglia of the nervous system.

Truman and Endo found that the emerging adult of the tobacco hawkmoth Manduca behaves in the same way. It likewise pupates in the soil, and so long as the emergent moth is confined it shows intense digging behaviour, and the spreading of the wings is suppressed, sometimes for 24 hours.

providing insulating layers of varying thickness and spatial structure, and in the interception of precipitation and its subsequent evaporation directly from leaf surfaces.

The quantification of these parameters, however, is extremely difficult. One of the most useful approaches has been the development of detailed models which attempt to account for all of the microclimatic and spatial variables, each of which can be determined individually (for example, Monteith, Symp Soc. exp. Biol., 19, 205; 1965). Various attempts have been made to compare water losses from deciduous and coniferous stands by observational rather than theoretical methods, but most of these have shown negligible differences during the summer months (for example Zahner, Forest Sci., 1, 258; 1955); no reliable data are
The stimulus which maintains the inhibition comes from the head: decapitated moths spread their wings immediately, regardless of whether they are confined. Moths decapitated at the very moment of eclosion, however, show neither wing inflation nor wing folding. But if decapitation is delayed until five seconds after emergence, the full wing-spreading behaviour occurs.

This effect of the brain is not dependent on the nerve supply; it is the result of the neurosecretory 'eclosion hormone': a brain removed from the pupa and implanted into the abdomen of a decapitated pupa is wholly effective in evoking complete wing spreading. The suboesophageal ganglion is also necessary for wing spreading; but this seems to be a neural effect on movement. The hormone bursicon, set free from the abdominal nerve cord, will cause neither wing inflation nor wing folding; it has two important functions: it serves to plasticise the cuticle (as was shown by Cottrell in the blowfly) and it sets in motion the hardening of the cuticle which, in turn, apparently dictates by feedback to the central nervous system the timing of the wing-folding movements.

In brief the eclosion hormone, discovered by Truman a few years ago, not only initiates emergence, but also wing spreading, which is brought about by a central motor programme involving neural and hormonal stimuli and some degree of sensory feedback. available for longer periods covering the winter season, when evergreens may continue to transpire and also to intercept more rainfall than deciduous trees. Comparative data between forest stands on different sites will always be somewhat suspect because of possible differences in the soil water storage capacities, hence long term studies on a single site where deciduous trees have been replaced by conifers seems to be the most hopeful approach to this problem.

The results of just such a study have now been published by Swank and Douglass (Science, 185, 857; 1974). Their study area is in the Appalachian Mountains of the south-western region of North Carolina, originally bearing oak-hickory forest. Streamflow studies were carried out on selected watersheds within the area over a period of ten 